Revista Iberoamericana, Vol. LXXXII, Núm. 254, Enero-Marzo 2016, 15-26

\title{
EL CUERPO FEMENINO Y TRANGRESIÓN EN EL CUARTO MUNDO DE DIAMELA ELTIT
}

\author{
POR \\ Mónica del CARmen Barrientos \\ University of Pittsburgh
}

Trabajar con pedazos de materiales, con retazos de voces explorar vagamente (digo, a la manera vagabunda) los géneros, la mascarada, el simulacro y la verbaliza emoción, ha sido mi lugar literario.

Diamela Eltit, "Emergencias"

Durante la última década, la escritora Diamela Eltit se ha erguido como una de las voces más interesantes de la narrativa chilena e hispanoamericana. Al intentar un recorrido de todos sus textos, desde Lumpérica (1983) hasta Fuerzas especiales (2013), se puede observar que existen ciertos tópicos que son recurrentes en sus obras, como la marginalidad, representada en diferentes figuras. En sus textos se puede observar que existen ciertas estructuras de significación que se organizan bajo instancias marginales donde prevalecen las figuras de vagabundos, torturados, incestuosos, niños sin nacer, esquizofrénicos. Además, el descentramiento de la palabra dentro del proceso de escritura, tema principal y obsesivo dentro de los textos, se presenta por medio de quiebres sintácticos, modos narrativos, explosión de géneros, etc. Pero también se observa la materialidad del cuerpo femenino como centro de las relaciones de poder. De este modo, se distingue en la narrativa de Eltit un hilo que atraviesa su producción y que se relaciona con el fragmento y el residuo. Asimismo, otro elemento que se mantiene durante toda la obra de Eltit es la voz narrativa que va adquiriendo modos y formas múltiples, ya sea dentro de una obra específica o a lo largo de ella. A este respecto, la misma autora afirma que su intención es "[t]rabajar con pedazos de materiales, con retazos de voces, explorar vagamente (digo, a la manera vagabunda) los géneros, la mascarada, el simulacro y la verbalizada emoción, ha sido mi lugar literario" ("Errante, errática" 20). De este modo, un análisis de la obra de Diamela Eltit debe incluir el cuerpo como centro de relaciones de poder y la voz narrativa que intenta hacerse cuerpo para comunicar una situación de violencia. En las novelas de Eltit, la materialidad biológica del cuerpo es el depósito de una violencia histórica que intenta someterlo por medio de diferentes formas de normalización. Sin embargo, este cuerpo también es una forma 
de resistencia a cualquier modelo autoritario que quiera imponerse, llámese 'Sistema' o 'Historia', que inscribe en la materialidad del cuerpo -en la piel o los órganos- la memoria narrativa para re-contar el pasado y criticar el presente. Así, la intención es elaborar una lectura política de la historia a través del cuerpo en la narrativa de Eltit para poder leer los signos del desamparo social y mental de una sociedad que intenta borrar continuamente su pasado.

Al cumplirse más de una década de la aparición de El cuarto mundo (1988), quisiera realizar un homenaje a esta obra y elaborar una nueva lectura que comprende otras perspectivas ideológicas, filosóficas, estéticas y literarias. Alejarnos de esas primeras explicaciones impresionistas y crear un nuevo espacio cultural donde las relaciones que establecen dichos textos con otros y con ellos mismos carecen de posiciones jerarquizantes, impulsando pluralidades y búsquedas tan múltiples que hacen difusa las fronteras, en un intento de ampliar el espacio donde la diversidad y el debate deben legitimar su condición textual. Es por esto que el presente artículo tiene por objeto demostrar que el cuerpo de los protagonistas es el arma mediante la cual se enfrentan a las diferentes formas de poder que los acosan. Además, se mostrará que el cuerpo femenino tiene una relación directa con el texto, llegando a configurarse como uno solo. De esta forma, cuerpo y texto serán una sola conjunción que implica el desarrollo de una metanarrativa.

El cuarto mundo es una de las novelas que ha tenido bastante atención por parte de la crítica chilena y extranjera. En Chile, Ignacio Valente, crítico del diario conservador El Mercurio, en una de las primeras críticas que aparecen en la prensa, afirma el carácter experimental diciendo: "Ignoro si alguien entenderá esta escritura febril de la segunda parte. En todo caso, y aun a pesar de esa oscuridad, debe reconocerse la capacidad que estas páginas tienen de ser leídas como un oscuro poema" (4). Frente a esta incomprensión que Valente, por un lado admira, María Inés Lagos, quien publica un artículo en la primera edición compilada de la obra de Eltit por Juan Carlos Lértora, afirma que El cuarto mundo es la alusión a un "término con que se denomina a los cinturones de miseria en las sociedades industrializadas, sugiere la diversidad de los mundos contenidos en una misma sociedad" (136), lo que ubica a la novela en un lugar más allá del escenario chileno. Fuera de Chile y desde una perspectiva que une el psicoanálisis con el trauma del país, Aúrea Sotomayor observa en la novela la relación de tres elementos unidos por un hilo de sangre: el útero, el cuarto y el país: " $E l$ cuarto mundo exhibe la subversión de las genealogías femeninas, representadas por la madre, la hija y el hijo nombrado María Chipia al nacer" (103). La hija, producto de la relación incestuosa de los mellizos, se configura en una obra que no es de carne, sino de "palabras alumbradas por el deseo como otro espacio de la subversión" (Sotomayor 114). Profundizando la línea psicoanalítica, Mary Green afirma que la novela es la representación ficcional de la construcción del género: "In El cuarto mundo, the two differential categories that are brought are those of sexual differences, and the central

Revista Iberoamericana, Vol. LXXXI, Núm. 254, Enero-Marzo 2016, $15-26$ ISSN 0034-9631 (Impreso) 
image of fraternal twins can thus be moved beyond its literal significance to address the status of male-female relations in Chilean society" (74). Finalmente, en una excelente aproximación filosófica y política, Sergio Rojas afirma:

Entonces, como límite, el cuarto mundo queda estructuralmente relacionado con la noción misma de lo social como una comunidad posible, proyectada a partir de su desarrollo material. Es lo otro de lo propiamente social, pues consiste en la alteridad que lo social mismo requiere para operar como normalización de la subjetividad, lo social como socialización del sujeto, como iniciación de éste en la vida individuada. (82)

A pesar de las diferentes perspectivas que puedan tener los análisis, existen elementos en común, como la marginalidad, la construcción de una identidad "sudaca" y genérica, la metanarración para mostrar el proceso de creación de la novela misma. En este análisis, nos centraremos en cuatro perspectivas de análisis. En primer lugar, abordaremos las relaciones de poder-desde la perspectiva de Michel Foucault- que se generan dentro de la obra, por medio de la vigilancia paterna y de la tercera hermana. El siguiente punto de análisis serán las "subjetividades errantes" de la novela, es decir, de qué forma el concepto de identidad es torcido o explotado para poner en cuestión el concepto de identidad única. El tercer punto es un análisis de los espacios de la novela, donde el útero, la casa y la ciudad se transforman en espacios rizomáticos que se desterritoralizan, haciendo de ellos espacios vigilados y cerrados, pero que con la actuación de los mellizos, logran crear puntos de fuga para romper la vigilancia y la normalización. Finalmente, analizaremos la relación cuerpo-texto que se produce en el proceso de creación-gestación de esta "obra sudaca terrible y molesta"(Cuarto mundo 88).

El cuarto mundo es una novela que centra su narración en la figura de dos hermanos mellizos. En su aspecto formal consta de dos partes: Capítulo I, "Será irrevocable la derrota", narra la gestación violenta del niño mientras su madre se encuentra enferma un día siete de abril. Esta primera parte será narrada por la voz del niño desde el útero materno con una forma y sentido muy racional, ya que el niño critica las actitudes de sus progenitores y el espacio en que habita. El carácter lógico hace a esta voz masculina por excelencia. Pero este carácter racional es traicionado por las opiniones vertidas hacia el mundo, por lo tanto, existe una fisura entre el pensamiento lógico que debe tener como resultado una adecuación con el mundo. El micro espacio (útero) del niño es inundado, al día siguiente de su gestación, por otra escena violenta: el padre nuevamente viola a la madre y gesta otro bebé que ahora será una niña. El niño, ante la llegada de esta persona que desde un principio rechaza, lo hace vivir y sentir momentos extremos. Posteriormente, la madre tiene otra hija, Maria de Alava, eterna rival de los mellizos. Los hermanos mellizos con el tiempo se irán compenetrando hasta identificarse el uno con el otro. Esta primera parte finaliza con el adulterio perpetrado por la madre y que los lleva al encierro definitivo.

Revista Iberoamericana, Vol. LXXXII, Núm. 254, Enero-Marzo 2016, $15-26$ ISSN 0034-9631 (Impreso)

ISSN 2154-4794 (Electrónico) 
El segundo capítulo, "Tengo la mano terriblemente agarrotada", comprende un cambio de voz. Ahora es la hermana melliza la que presenta la historia, por lo tanto, su lenguaje será completamente diferente al anterior: lenguaje pulsional, irracional, con una fuerte carga de metáforas y escenas eróticas. En esta parte se soluciona la duda con respecto a los nombres de los hermanos: el niño se llama María Chipia y se ha travestido en virgen, mientras que su hermana espera un hijo suyo. El incesto es el tema de la novela y esta segunda parte se desarrolla en torno al hijo que va a nacer y que se vaticina será un monstruo porque viene deforme. El escenario, por lo tanto, será en primera instancia el útero materno desde donde habla el primer narrador masculino, para luego, después del nacimiento, localizarnos en la casa familiar, en la cual los mellizos van desarrollando sus vidas y experiencias. Es aquí donde los padres han pasado a constituir un segundo plano, transformados en espectadores voyeristas de las perversiones de sus hijos.

\section{EL CERCO DEL PODER}

El concepto de poder ha sido uno de los temas que ha tenido mayor análisis en este inicio del siglo. Sin duda, autores como Michel Foucault, Gilles Deleuze, Félix Guattari, entre otros, son referencias importantes para un análisis acerca de las relaciones de poder y de sus efectos en los cuerpos. Estos discursos se confrontaron a las proyecciones del canon filosófico y literario, que implicaron no sólo en la sociedad, sino también en los cuerpos de los individuos. De esta forma, podríamos plantear un escenario que representa la transformación material del paradigma del poder, así como las subjetividades que lo conforman.

Los postulados de Foucault han pavimentado el terreno para una visión crítica de prácticas de poder en la actualidad, al mostrar el tránsito de una sociedad disciplinaria a una de control. La sociedad disciplinaria gobierna por medio de dispositivos que producen costumbres y hábitos en la sociedad "para garantizar la ordenación de las multiplicidades humanas" (Vigilar 125). Su intención es asegurar la obediencia a través de instituciones disciplinarias como el colegio, la iglesia, la prisión, etc., que fijan su mirada en el sujeto, el individuo, quien debe asumir la obediencia o convertirse en un proscrito excluido al rechazar este ordenamiento. Es por ello que en El cuarto mundo las relaciones de poder también son manejadas a través de máscaras que se movilizan de acuerdo a lo que se requiera. Esto quiere decir que las relaciones de poder tienen su asidero más material en el núcleo mismo de la sociedad, o sea, la familia: "de asirlo en sus formas e instituciones más regionales, más locales, sobre todo allí donde, saltando por encima de las reglas del derecho que lo organizan y lo delimitan, se extiende más allá de ellas" (Foucault, Microfísica 142). Por lo tanto, el poder se encuentra en todas partes formando una red en la cual están sumergidos todos los individuos "reales", o sea, personas no sólo jurídicas, sino niños, ancianos, mujeres, madres, esposos, etc.

Revista Iberoamericana, Vol. LXXXI, Núm. 254, Enero-Marzo 2016, $15-26$ ISSN 0034-9631 (Impreso)

ISSN 2154-4794 (Electrónico) 
La familia en El cuarto mundo se presenta como el espacio en el cual los hermanos se desarrollan y van adquiriendo las formas y características que los consumirán en el encierro definitivo. Desde las primeras páginas se observa que el poder aparece representado en la violencia sexual: el padre viola a su esposa, aprovechando la enfermedad de ésta. Los hermanos, por lo tanto, serán hijos de la violencia por la cual han sido engendrados y que los marcará por el resto de sus vidas. Bajo este ámbito simbólico, el niño es quien representa una parte del poder que comprende la mirada racional del mundo y la violencia de sus acciones: "Ejercí la estricta dimensión del pensar. Antes sólo me debatía entre impresiones que luego transformaba en certezas" (Cuarto mundo 15). La contraparte del hermano es su melliza, quien actúa como una constante resistencia a este orden lógico y masculino que el niño desea establecer: "Yo, una de ellos, caí en laxitud después de la lujuria, sin forma ni cuerpo y con una espantosa fractura moral" (84). En los primeros años de vida, cada uno intenta atraer la atención de sus padres, así la niña es quien dice la primera palabra; este hecho produce el primer fracaso del niño que, a modo de revancha, da el primer paso.

El ingreso al mundo racional se da a través del lenguaje -símbolo de la entrada al mundo masculino - quien es dado por el padre, ya que María de Alava, la tercera hermana, comienza a hablar guiada por éste. De esta forma, la niña viene a ser una vigilancia constante en los mellizos, quienes han ido escapando del mundo racional que trataba de dominarlos. Por otro lado, el niño ha iniciado un cuestionamiento al sistema de orden que se mantiene en su casa. La duda y la falta de base en la "racionalidad" que había adquirido, y la irremediable caída de la familia, lo obliga a acercarse a su hermana, quien porta las obsesiones y el deseo heredados de los sueños de su madre, pero que hace fortalecer un lazo que mantienen juntos desde antes del nacimiento. Esta fisura en la identidad del niño irá abriéndose cada vez más, hasta llegar a la ruptura total cuando la madre facilite la entrada de la enfermedad en la casa. Es necesario indicar que la infidelidad del padre era un hecho conocido y aceptado por la familia, especialmente por la esposa, lo que le permitía saltarse el protocolo del matrimonio. Pero la infidelidad de la madre fue lo que precipitó la "irrevocable derrota" de la familia. Este hecho es consignado como una fatalidad extrema, como un trauma insuperable: "Mi madre precipitó el encierro. Desplomó el universo, confundió el curso de las aguas, desenterró ruinas milenarias y atrajo cantos de guerra y podredumbre. Mi madre cometió adulterio" (75).

Con esta falta materna concluye la primera parte narrada por el niño. En la segunda parte, existe un cambio de narrador donde es la niña quien relata la historia. La familia se encuentra encerrada y los padres han perdido completamente la autoridad y se han transformado en voyeristas de sus propios hijos. La niña espera un hijo de su hermano quien se ha travestido en virgen, pero la presencia de María de Alava viene a representar el orden paterno que se pensaba ausente. Ya que la prole ha caído inevitablemente, María de Alava se convierte en una especie de protección, incluso acepta la llegada del

Revista Iberoamericana, Vol. LXXXII, Núm. 254, Enero-Marzo 2016, $15-26$ ISSN 0034-9631 (Impreso)

ISSN 2154-4794 (Electrónico) 
niño y desea cuidarlo. Por esta razón, las relaciones de poder son configuradas en dos polos: por un lado el paterno, encarnado en una figura supuestamente femenina, pero con rasgos viriles; y por otro, el de los mellizos, herederos directos de las perversiones maternas. Entre ambos se intenta crear un nexo a través de la palabra, por ello, la confesión constante de los hermanos se transforma en un ritual de purificación ante las culpas cometidas.

\section{SuBJETIVIDADES ERRANTES}

En una entrevista con Michael Lazzara, Diamela Eltit se plantea la siguiente pregunta: “Cómo tratar de limar, hasta donde se pueda, todo este proyecto burgués que intenta modelar de una manera asimétrica al sujeto popular?" (23). El problema entonces, radica en cómo representar al sujeto subordinado, marginal, desde su localización misma y no desde una mirada paternalista o dentro del concepto de "el otro". En otras palabras, lo que se intenta es dar estatus a esas voces que han sido tradicionalmente silenciadas por los discursos oficiales.

La marginalidad atravesada por la violencia, la transgresión, la psicosis y la desintegración de la sociedad, son algunos de los temas transversales en la obra de Eltit. Sin embargo, el proyecto intenta cuestionar ese modo de "hablar" que podría representar el marginal que no puede ser el mismo que lo ha mantenido en la periferia, es decir, la intención es eliminar la mirada desde el centro para hablar de aquellos que habitan (en) el margen. Es por ello que el concepto de "víctima" no debe ser entendido como aquel que padece o sufre reiterativamente alguna injusticia. El filósofo francés Alan Badiou rechaza la idea de víctima porque ésta se define desde el interior de una visión política, por lo tanto, su término es variable. Además, la víctima es "revelada por el espectáculo del sufrimiento" (Badiou) asociado a un sentimiento de piedad. Es precisamente este sentimiento el que las obras de Eltit evitan. Los personajes son efectivamente sufrientes, pero no en términos negativos, sino que este sufrimiento y espectáculo se revierte en un espacio político de cuestionamiento. Así, la mirada del espectador o lector puede ser de adhesión o rechazo, pero ya no de misericordia. Y es este punto lo que produce la molestia en el lector, porque debe tomar posición frente a este espectáculo de los marginales, una decisión que es, además, política.

En El cuarto mundo existen dos narradores que, en cada capítulo, presentan el mundo desde su propia perspectiva, racional y masculina en la primera parte, y caótica y femenina en la segunda parte. De esta forma, la identidad pasa a ser una pieza clave para el análisis de la novela, ya que nos encontramos con una obra que produce un estallido al concepto mismo de sujeto, y por lo tanto, de identidad. El sujeto ahora es entendido no como un ser que posee rasgos fijos y definibles, sino como una subjetividad que está en constante cambio, es heterogéneo, múltiple y su definición sólo puede encontrarse fuera de los diccionarios o de cualquier categorización centralizadora.

\footnotetext{
Revista Iberoamericana,
ISOl.
} 
Paul Ricoeur en su análisis acerca del concepto de "identidad" propone una reconstrucción filológica del concepto, demostrando que esta palabra que nombra (o renombra) al "yo" frente al lenguaje posee no sólo una historia intrincada, sino procesal, o sea, una actualidad potencialmente abierta, es decir, una "subjetividad sin anclajes" (XIX). ${ }^{1}$ De esta forma, afirma que se debe pensar la identidad desde su narrativa, es decir, desde su relato de construcción y autorreflexión. Por esta razón, hemos decidido hablar de "subjetividad" para referirnos a los personajes, ya que así, se ubica a los sujetos dentro de un cuadro de múltiples posibilidades, como la fuerza de un signo concurrente, siempre abierto al entrecruzamiento con todos los otros signos. Lo anterior permite pensar la identidad fuera de las codificaciones previstas por discursos disciplinarios y poner en duda (o en crisis) las nociones tradicionales, restrictivas y sancionadoras de la identidad como homogeneidad, semejanza y valoración, para hacer emerger esta subjetividad plural, heterogénea, múltiple que designa la semejanza no como homogénea, sino como analógica, o sea, que descubre lo similar en dos cosas distintas.

En la novela, los personajes son "subjetividades errantes", en el sentido de no permanecer dentro de una forma definible o con ciertas características que permitan crear un estereotipo de ellos. Todos los personajes son seres que no aceptan una categorización porque se encuentran abiertos a cualquier cambio, están en constante movimiento y poseen una subjetividad tan compleja que tratar de crear un "perfil" de ellos es completamente imposible. La única línea en común que tienen es estar en constante crisis, o sea, se mantienen dentro de las múltiples rupturas con su contexto, cualquiera que este sea. La subjetividad múltiple no se da en un solo personaje, sino en la dualidad binaria, correspondiente a la teoría del sujeto que postula Julia Kristeva y la relación de feminidad-diferencia en la cual se han conjugado en una sola forma tanto la "instancia simbólica" (lo normativo o masculino paterno) que corresponde a la figura del hermano en la primera parte, y la "instancia semiótica" (pulsional femenina materna) que se relaciona con la hermana de la segunda parte. Para Kristeva, la gestación es un acontecimiento innombrable al que llama "el bullicio subterráneo de segundos que se pliegan en espacios inimaginables” (Historias 210). Así, el cuerpo materno desestabiliza lo simbólico por la abstracción que contiene la gestación. El primer capítulo de la novela tiene como narrador al niño, es por este motivo que el texto se presenta con una lógica discursiva propia de la razón masculina; pero a medida que se va acercando a su hermana, su racionalidad lo irá traicionando hasta que la familia cae y se inicia el segundo capítulo donde la voz ahora es de la hermana. En esta parte, la lógica masculina está completamente obliterada por un lenguaje corporal, donde el sueño, lo erótico y lo marginal se convierten en los tópicos del texto. De la unión incestuosa de ambos surge el engendro mestizo, pero para ello debieron reunirse las dos instancias, la masculina y la femenina, para dar origen a

Para un análisis más profundo acerca de la identidad en Ricoeur, ver el Prólogo de su libro.

Revista Iberoamericana, Vol. LXXXII, Núm. 254, Enero-Marzo 2016, 15-26 ISSN 0034-9631 (Impreso)

ISSN 2154-4794 (Electrónico) 
algo que supera la diferencia sexual que marca a nuestra cultura. Es por ello que se le atribuye importancia al sujeto femenino de esta novela, porque es quien permanece y el que se presenta como transgresor. Lo racional masculino del niño se irá perdiendo en favor de lo pulsional femenino de la hermana, quien además, ha heredado la perversión, a través de los sueños de la madre. De esta forma, en la novela se encuentran subjetividades errantes, en el sentido de no ser personajes que se hallan dentro de ciertos parámetros de definición. La (des)identidad constituye la fragmentación con la que los personajes se identifican y que hace posible la dislocación de los poderes dominantes al no tener un punto fijo del cual afirmarse. A pesar de conformar una familia "tradicional", los personajes viven en el margen de una ciudad sudaca, y por ello portan en sus cuerpos la perversión. Todos estos personajes exceden la normalidad impuesta, ya sea por su apariencia grotesca de locura o por sus prácticas excesivas y abyectas, constituyendo un problema para el sistema. La deformidad y el defecto se constituyen en la fractura corporal y textual que estos personajes encarnan por medio de la monstruosidad que es la figura que representa de mejor forma la resistencia y la transgresión en una sociedad disciplinaria. De este modo, la marginalidad a la que están sometidos es una decisión política, una acción que incorporan en sus discursos y sus cuerpos. Es por esto que estas figuras en la novela siempre provocan un golpe a la mirada, ya que su apariencia estética y sus comportamientos sociales están completamente "anormalizados". Con esto quiero afirmar que los personajes no son subordinados inactivos. Ellos portan, en la conciencia de la subordinación, las herramientas que les permiten crear la grieta a ese sistema hegemónico que intenta marginalizarlos. El desafío a la organización social, la fisura al cuerpo y el lenguaje, el torcimiento de la lengua, son algunos de los puntos de fuga que ellos utilizan para instaurarse porfiadamente en el escenario de la historia.

\section{ESPACIOS FRACTURADOS}

El espacio en la novela de Eltit se caracteriza por ser otra forma de extensión o superficie de la escritura misma. Es un espacio principalmente urbano que funciona no como una metáfora, sino más bien como recurso que produce representaciones incompletas. Es un espacio rizomático que prolifera dependiendo de cómo el personaje lo habita. Es necesario recordar que Guattari define el territorio como "sinónimo de apropiación, de subjetivación encerrada en sí misma" (372), pero que puede desterritoralizarse, es decir, abrirse a líneas de fuga. Esta proliferación no provoca el extravío de los personajes, sino que la misma ciudad es el recurso para dar lugar a ese disturbio de los personajes y generar redes desterritorializantes para propiciar la desbocadura de su propia interioridad. De este modo, el útero, la casa y la ciudad despliegan una trama de presencias y ausencias, huellas y sombras que delatan la incesante actividad de estos cuerpos marginalizados. Detrás de la experiencia vivida

Revista Iberoamericana, Vol. LXXXII, Núm.254, Enero-Marzo 2016, $15-26$ 
en las construcciones, los personajes intentan comunicar aquello que queda invisible al ojo cotidiano; son, por lo tanto, espacios residuales y vacíos que convocan una memoria simbólica que esconde la huella de su historia. Además de los conceptos de rizoma y desterritoralización de Deleuze y Guattari, otro planteamiento importante es el de Doreen Massey, quien comprende el espacio como un lugar en que se crean las identidades y depende de las articulaciones entre el sujeto político y el lugar, por lo tanto, no es estático o pasivo, sino que se encuentran en constante trasformación. En Space, Place, and Gender, afirma que "[...] the spatial is thought of in the context of space-time and formed out social interrelations at all scales, then one view of a place is a particular articulation of those relations, a particular moment of those networks of social relations and understandings"(9). Por lo tanto, la identidad de un lugar no es fija, porque las relaciones que se dan al interior de éste son dinámicas; pero lo más importante es entender que los sujetos se construyen en este punto de intersección, por lo que la identidad posee una variedad de discursos, de tiempos y de espacios. Así, una de las interacciones que se forman en el territorio son las relaciones de poder que atraviesan los cuerpos geográficos y físicos.

En El cuarto mundo encontramos tres espacios fundamentales que forman una arqueología latinoamericana desde el inconsciente de la memoria: la casa, el útero y la ciudad. Estos tres espacios funcionan como espejos deformados que replican las acciones y perversiones de sus habitantes, ya que desplazan las ruinas de la ciudad hacia los espacios más íntimos de la familia como centro carcomido por el poder. El primer espacio habitable es el alucinado vientre materno donde los hermanos mellizos inician su proceso de conformación de una identidad. Desde aquí, el hermano mellizo, María Chipia, inicia su trabajo de pensar y logra reconocer las habilidades de su hermana para traducir los sueños maternos. Ambos personajes, entrelazados por sus cuerpos, enfrentan las pesadillas de la madre y el terror de la ciudad que les espera después del alumbramiento. La conformación de la familia se produce en el espacio saturado de la casa, que es la extensión del útero materno. La casa es un espacio vigilado por el padre y por María de Alava, la tercera hermana donde "todo estaba racionalmente medido en ella con la razón que tan bien identificábamos en mi padre" (39), quien intenta mantener el orden y control de los mellizos. Mientras la familia se mantuvo dentro de sus límites, los mellizos logran contener sus apetitos heredados por la madre. Sin embargo, la salida al exterior provoca el cambio:

Nuestra salida al exterior fue verdaderamente estremecedora. La ciudad, tibiamente sórdida, nos motivó a todo tipo de apetencias y activó nuestras fantasías heredadas de mi madre. Se podía palpar en el espesor ciudadano, el tráfico libidinal que unía el crimen y la venta. Los bellos torsos desnudos de los jóvenes sudacas semejaban esculturas móviles recorriendo las aceras. En ese breve recorrido nuestros ojos caían en una bacanal descontrolada. (40)

Revista Iberoamericana, Vol. LXXXII, Núm. 254, Enero-Marzo 2016, 15-26 ISSN 0034-9631 (Impreso)

ISSN 2154-4794 (Electrónico) 
La salida y el contacto con la ciudad permiten a los mellizos reconocerse como parte de una comunidad marginal. A diferencia de sus padres, quienes siempre intentan huir de la casa y la ciudad, porque ellos se identifican con el primer mundo, los mellizos reconocen su estigma sudaca.

Es importante señalar que El cuarto mundo, dentro de la obra de Eltit, inicia la etapa de crítica al sistema neoliberal en Chile y América Latina. La familia debe ocultarse en la casa por la vergüenza del adulterio materno y desde allí aliviar las culpas del adulterio y el incesto de los mellizos por medio de un homenaje a la raza sudaca, mientras la ciudad se devastaba poco a poco. El caos de la ciudad es percibido desde el interior de la casa, al igual que los mellizos percibían el mundo de afuera desde el útero. La percepción se relaciona con el advenimiento de la nación más poderosa del mundo, mientras las hogueras van llenando la ciudad. María de Alava y los padres intentan huir de la casa y del origen tercermundista para que los mellizos se queden solos y disfruten el estigma sudaca. La huida se produce al amanecer mientras la ciudad termina de colapsar y se produce la venta:

Se vende el trigo, el maíz, los sauzales, a un precio irrisorio, juntos a los jóvenes sudacas que han sembrado. [...] El dinero caído del cielo vuelve al cielo y los vendedores venden incluso aquello que no les pertenece.

La ciudad colapsada es ya una ficción nominal. Sólo el nombre de la ciudad permanece, porque todo lo demás se ha vendido en el amplio mercado. [...]

[...] La transacción está a punto de concluir, y en el dinero caído del cielo está impresa, nítidamente, una sonrisa de menosprecio a la raza sudaca. (127-128)

De este modo, el espacio narrativo es simbólico y funcional y se encuentra permanente vigilado. Sin embargo, se produce la fisura al interior del mismo para permitir el desencadenamiento de las múltiples subjetividades que cuestionan esa misma vigilancia y permiten la creación de una resistencia comunitaria que se define como sudaca y marginal.

\section{"UNA OBRA SUDACA TERRIBLE Y MOLESTA"}

El poder penetra en los cuerpos individuales moldeándolos y normalizándolos. Esta suma de efectos constituye el cuerpo social, conformado por todas las personas de un mismo espacio en el cual se produce el juego del poder, por lo tanto, para Michel Foucault no existe nada más material, más físico, más corporal que el ejercicio del poder, porque es el cuerpo su primer efecto y su primer blanco. Todo el aparataje político o institucional funciona en torno a este juego; y el cuerpo de la mujer corresponde a una forma importante de manejo y regulación del poder, no sólo sobre la mujer específicamente, sino sobre la sociedad, pero que tiene como consecuencia inmediata y directa la formación

Revista Iberoamericana, Vol. LXXXII, Núm. 254, Enero-Marzo 2016, $15-26$ ISSN 0034-9631 (Impreso)

ISSN 2154-4794 (Electrónico) 
de "la mujer". Foucault señala que la "histerización del cuerpo de la mujer" (Historia 127) es un triple proceso donde su cuerpo fue calificado (y descalificado) como un cuerpo saturado de sexualidad. Bajo este concepto, el cuerpo pasó a conformar la lista de patologías, pero en este caso, no es adquirida, sino que es intrínseca, o sea, forma parte de su constitución misma. Esta noción del cuerpo de la mujer ha servido para que se produzcan y fomenten una serie de normas y reglamentos, apelando a la "esencia" o "naturaleza" femenina, con el fin de crear una estructura social donde la mujer se convierte en la guardiana del orden familiar, y por ende, social. Es por esta razón que los personajes de la novela utilizan sus cuerpos como contra-poder o resistencia, ya que ha sido éste el principal blanco para disciplinar a los sujetos. El cuerpo, emerge como lugar de resistencia al explotar sus zonas más reprimidas a través de diferentes perversiones sexuales como el incesto, el autoerotismo, el dolor/goce, etc. La condición perversa es vista desde la abyección que plantea Julia Kristeva como "aquello que perturba una identidad, un sistema, un orden. Aquello que no respeta los límites, los lugares, las reglas. La complicidad, lo ambiguo, lo mixto" (Poderes 11). El silenciamiento y las constantes intervenciones en aquellos espacios donde el logos fue predominante por medio de la voz docta (tribunales, escuelas, asambleas, etc.) provocaron la aparición de espacios y cuerpos que pierden las limitaciones de identidad. El cuerpo propio desaparece y se deja ocupar por los signos y las marcas de aquello que ha sido negado. Es por ello que los personajes, por medio de una performance, muestran orgullosamente las heridas auto-inferidas o producidas en el proceso de subjetivación, es decir, en la búsqueda de algún punto de fuga. Por esta razón, la escritura fuera del logos se presenta como una de las formas más acertadas para provocar la "solicitación" de la fijeza (Derrida 13). Hacer temblar y estremecer el pensamiento tradicional occidental y su forma lógica de concebir el mundo a través de la violencia y la jerarquía es la tarea que tiene este nuevo concepto de escritura. De este modo, las novelas de Eltit son el resultado de una territorialización de la escritura donde los narradores adquieren cuerpo en el proceso mismo de escribir. Por esto, el cuerpo y el texto se tornan fragmentados y abyectos. Hablamos de cuerpos autoflagelados, sudacas, incestuosos, lacerados y fragmentados. Así, la escritura funciona como un dispositivo que narra la violencia por medio de diferentes atentados al cuerpo. Los cuerpos en la narrativa de Eltit no son completos, sino que siempre narran fragmentos del propio cuerpo.

Así, en este proceso, la familia de El cuarto mundo, se va identificando con aquellos personajes que están en las afueras de la ciudad, "los sudacas", y con los rasgos que son asociados a ellos: incesto, infidelidad, violencia, sangre, etc. Después de la caída por el adulterio materno, la familia asume su condición, pero revirtiéndolo en un estado de superioridad: la raza sudaca tendrá primacía. De esta forma se crea alrededor de la casa un espacio sagrado donde el rito, la ceremonia serán las alabanzas a esta raza pervertida que espera, entre ceremonias y ritos, la llegada del hijo producto del incesto de los

Revista Iberoamericana, Vol. LXXXII, Núm. 254, Enero-Marzo 2016, $15-26$ ISSN 0034-9631 (Impreso)

ISSN 2154-4794 (Electrónico) 
hermanos. La gestación del niño se produce por una razón sagrada: pagar "las culpas familiares" (83). El niño será la "obra sudaca terrible y molesta" (88) que esta familia brinde a la raza. Como digno ejemplo de la especie sudaca, el niño será un engendro, un ser anormal físicamente que contendrá todas las perversiones que la familia, como representantes de la raza sudaca, ha desarrollado:

(El niño venía ya horriblemente herido.) (83)

(El niño venía con la paz cetrina de su mal semblante.) (84)

(Supe que el niño venía con el cráneo hundido.) (85)

Maria Chipia murmuró en mi oído que el niño nacería malformado. (90)

Todas las características que anuncian al bebé en gestación aparecen en pequeños fragmentos y son premoniciones, pero todas indican que el niño será un monstruo que causará repulsión, por lo tanto, será un digno sudaca.

El planteamiento perverso de los personajes no se mantiene únicamente en una explosión desenfrenada de ciertas pulsiones que se han mantenido reprimidas, sino que tienen una correlación directa con el quehacer textual. En la novela, cuerpo y texto se conjugan en una sola forma, se desarrollan paralelamente. Así, surge un cuerpo textual femenino o una sexualización del texto donde cuerpo y página, letra y gesto se graban en la textura, tanto de la piel como de la obra. La textualización se presenta de diferentes formas, pero teniendo como materialidad directa los cuerpos de los mellizos. En la primera parte se observa el carácter masculino del niño al identificarse con los rasgos racionales y una escritura lineal. La segunda parte, narrada por la niña que tiene un lenguaje pulsional, onírico lleno de quiebres y metáforas. Las dos formas, ya sea la racional y la pulsional, se unen en una sola, donde los hermanos, a través del incesto, gestan un hijo. Es, por lo tanto, el hijo que vendrá, el punto importante en toda la trama de la novela, ya que este hijo, producto de las perversiones de sus padres, es también el prototipo de la raza sudaca, marginal y miserable. La segunda parte se refiere únicamente a la espera de este niño que se presagia deforme y enfermo. Hacia el final, los padres y María de Alava abandonan el hogar y quedan los hermanos solos para la espera del nacimiento: "Lejos, en una casa abandonada a la fraternidad, entre un 7 y un 8 de abril, diamela eltit, asistida por su hermano mellizo, da a luz una niña. La niña sudaca irá a la venta" (128).

El hijo que tanto se esperaba por fin ha nacido. La niña es la novela, la gran obra monstruosa que ha sido gestada en el propio cuerpo del personaje, que es el producto de la mezcla de la instancia femenina y masculina que viene a dislocar toda forma de lenguaje de la narrativa oficial, ya que está construida a través del carácter híbrido de los padres y de las culpas y perversiones de la familia. Este engendro es, por lo tanto, algo monstruoso. La monstruosidad se encuentra en la aparición de un lenguaje no oficial que circula por la ciudad, en la exaltación de los deseos sometidos, en el carácter

Revista Iberoamericana, Vol. LXXXII, Núm. 254, Enero-Marzo 2016, $15-26$ ISSN 0034-9631 (Impreso) ISSN 2154-4794 (Electrónico) 
discursivo de esta "gran obra" que han gestado los hermanos. El niño monstruoso es la novela misma que se ha estado leyendo.

Sin embargo, y este es el punto más importante en mi reflexión, es que aunque estemos frente a personajes marginales o precarios, éstos alzan la voz y el cuerpo para denunciar con sus propios cuerpos. Por lo tanto, no estamos hablando sólo de cuerpos sufrientes que se convierten en espectáculo, sino "que la víctima sea testimonio de algo más que sí misma” (Badiou). No es sólo el cuerpo, sino un cuerpo que tiene una idea, un pensamiento. Badiou llama a este cuerpo separado del pensamiento "la esclavitud moderna", ya que el cuerpo se convierte en víctima o consumo, pero separado de un proyecto universal. Es por ello que la lucha de estos personajes es afirmativa, porque unen sus cuerpos a una idea y no sólo al sufrimiento personal. No son personajes pasivos o padecientes, sino más bien, seres que tienen agencia al decidir posicionarse en el margen del sistema y hacer de su propio cuerpo una página de la historia.

De esta forma, podemos concluir que la conjunción cuerpo-voz-escritura es fundamental para seguir el proceso narrativo de Eltit. Estas rupturas, que se producen en la piel y la página de los sujetos marginales, intentan desde el cuerpo mismo otra forma de discurso, una especie de testimonio alterno donde la herida, la atrofia y el corte son las formas de representación de aquello que es imposible testimoniar, como es la memoria del desastre. El cuerpo, la voz trastocada y la página, muestran la ruptura de la homogeneidad, la carencia de fundamento teleológico y la explosión de todas las formas fijas. Los residuos se esparcen en las páginas y los textos, haciendo que ellos funcionen diseminados, pero entrelazados por una subjetividad plural, múltiple, de modo que así "reviente en la letra la pesadilla de estas noches" (Eltit, Lumpérica 39).

\section{BiBLIOGRAFÍA}

Badiou,Alan. "Laidea dejusticia". <http://www.catedras.fsoc.uba.ar/heler/justiciabadiou. htm>. 2004.

Derrida, Jacques. La escritura y la diferencia. Barcelona: Anthropos, 1989.

Eltit, Diamela. El cuarto mundo. Santiago de Chile: Planeta, 1988.

"Errante, errática". Una poética de literatura menor: la narrativa de Diamela

Eltit. Juan Carlos Lértora, ed. Santiago de Chile: Cuarto Propio, 1993. 17-25.

Lumpérica. Santiago de Chile: Ediciones del Ornitorrinco, 1983.

Foucault, Michel. Historia de la sexualidad. Vol. I. La voluntad de saber. Madrid: Siglo

Veintiuno, 1991.

Microfísica del poder. Madrid: La Piqueta, 1992.

Vigilar y castigar: nacimiento de la prisión. Buenos Aires: Siglo XXI, 2002.

Green, Mary. Diamela Eltit: Reading the Mother. New York: Tamesis, 2007.

Guattari, Félix y Suely Rolnik. Micropolítica. Cartografias del deseo. Petrópolis:

Editora Vozes Ltda., 2005.

Revista Iberoamericana, Vol. LXXXII, Núm. 254, Enero-Marzo 2016, 15-26 
Kristeva, Julia. Historias de amor. México D.F: Siglo XXI, 2004. Poderes de la perversión: Ensayo sobre Louis-Ferdinand Céline. Buenos Aires: Siglo XXI, 1989.

Lagos, María Inés. "Reflexiones sobre la representación del sujeto en dos textos de Diamela Eltit: Lumpérica y El cuarto mundo". Una poética de literatura menor: la narrativa de Diamela Eltit. Juan Carlos Lértora, ed. Santiago de Chile: Editorial Cuarto Propio, 1993. 127-140.

Lazzara, Michael J. Diamela Eltit: Conversación en Princeton. Program in Latin American Studies. Princeton: Princeton UP, 2002.

Létora, Juan Carlos, ed. Una poética de literatura menor: la narrativa de Diamela Eltit. Santiago de Chile: Editorial Cuarto Propio, 1993.

Massey, Doreen B.. Space, Place, and Gender. Minneapolis: U of Minnesota P, 1994. Ricoeur, Paul. Sí mismo como otro. México: Siglo XXI, 1996.

Rojas, Sergio. Catástrofe y trascendencia en la narrativa de Diamela Eltit. Santiago de Chile: Sangría Editora, 2012.

Sotomayor, Áurea. “Tres caricias: una lectura de Luce Irigaray en la narrativa de Diamela Eltit”. Femina Faber. Letra, música, ley. San Juan: Ediciones Callejón, 2004. 91-120. Valente, Ignacio. "El cuerpo es un horror y una gloria: El cuarto mundo". Revista de los Libros de El Mercurio (21 mayo 1989): 1-4. 